\title{
CARACTERÍSTICAS E VISÃO DO CORPO DOCENTE DE UMA ESCOLA RURAL DE SELVÍRIA (MS), DURANTE PROCESSO DE IMPLANTAÇÃO DOS PRINCÍPIOS DA EDUCAÇÃO DO CAMPO
}

\author{
VISION AND CHARACTERISTICS OF FACULTY OF THE RURAL SCHOOL \\ AT SELVÍRIA (MS), DURING THE PROCESS OF IMPLANTATION OF FIELD \\ EDUCATION PRINCIPLES
}

\author{
LAS CARACTERÍSTICAS Y LA VISIÓN DEL CUERPO DOCENTE DE \\ UNA ESCUELA RURAL DE SELVÍRIA (MS) DURANTE EL PROCESO DE \\ IMPLEMENTACIÓN DE LOS PRINCIPIOS DE LA EDUCACIÓN DEL CAMPO
}

\author{
Divanir Zaffani Sant'Ana - Universidade Estadual Paulista - Ilha Solteira - São Paulo - Brasil \\ nyllzaffani@hotmail.com \\ Antonio Lázaro Sant'Ana - Universidade Estadual Paulista - Ilha Solteira - São Paulo - Brasil \\ lazaro@agr.feis.unesp.br
}

\section{Resumo}

A educação do campo surgiu da luta de vários agentes sociais em oposição às concepções de uma educação rural desvinculada da realidade dos alunos, visando a revalorizar sua cultura, por meio de conteúdos e metodologias relacionadas ao seu cotidiano. Dessa forma, este estudo busca contribuir com a investigação a respeito da educação no meio rural, a partir de uma pesquisa realizada na Escola Municipal Rural São Joaquim Pólo, em Selvíria (MS), com o objetivo de levantar as características e as percepções do corpo docente em relação à escola e aos alunos, e verificar se estavam sendo utilizados os princípios pedagógicos e metodológicos preconizados pela educação do campo. Além da pesquisa em fontes secundárias e por meio de observações diretas, foi aplicado um questionário a 10 professores da escola. A diretora também respondeu a um questionário específico e foi gravada uma entrevista com ela e com a coordenadora pedagógica. A pesquisa detectou vários problemas relacionados à infraestrutura física da Escola, como a insuficiência de salas de aulas e de material pedagógico, a falta de alojamento para os professores, além de deficiências no transporte escolar e nos meios de comunicação, mas estes aspectos não impediram que a escola se constituísse em uma experiência (em construção) importante de educação, na medida em que busca considerar as especificidades dos alunos do campo.

Palavras-chave: educação do campo, caracterização dos educadores, percepção dos professores, infraestrutura da escola.

\begin{abstract}
The field education arose from the struggles of many social agents in opposition to the conceptions of a rural education unlinked to students reality, aiming to revalue their culture, by means of subjects and methodologies related to students everyday. This study looks forward to contributing with the searching on the state of the rural education, with its initial search performed in São Joaquim Pólo Municipal Rural School, at Selvíria (MS), which had as objective to rise the characteristics and perceptions of the faculty related to school and to students, and to verify if the pedagogical and methodological principles of the field education were being used. Beyond the search in secundary sources and direct observations, was administered one specific questionary to ten teachers of the School. The principal, also answered a specific questionary and was recorded a interview with the principal and with the pedagogical coordinator. The research detected many infrastructure problems at school,
\end{abstract}


as insufficient classrooms and pedagogical material, lack of accommodation for the teachers and deficiencies on the school transport and on means of communication, but these aspects didn't block that the school to constitute in an important education experience (in construction), as in it aim to consider the rural students specificities.

Key words: field education, teachers characterization, teachers perception, school infrastructure.

\section{Resumen}

La educación del campo surgió de la lucha de varios agentes sociales en oposición a las concepciones de una educación rural desvinculada de la realidad de los estudiantes, con el objetivo de revalorizar la cultura de los mismos a través de contenidos y metodologías relacionadas con la vida cotidiana de los estudiantes. Este estudio busca contribuir con la investigación sobre el estado de la educación rural, a partir de una pesquisa llevada a cabo en el Municipal Rural San Joaquín Polo, en Selvíria (MS), cuyo objetivo era levantar las características y percepciones de los profesores acerca de la escuela y los estudiantes, y ver si están siendo utilizados los principios pedagógico y metodológicos recomendados por la educación del campo. Además de la investigación en fuentes secundarias y observaciones directas, se administró un cuestionario a 10 docentes de la escuela. La Directora también respondió a un cuestionario específico y fue grabada en una entrevista con esta y con la Coordinadora Pedagógica. La pesquisa detectó varios problemas de infraestructura física de la Escuela, tales como la insuficiencia de aulas y material didáctico, la falta de alojamiento para los profesores y el transporte escolar y en los medios de comunicación, pero estas cuestiones no impidieron que la escuela si se constituise en una experiencia (en construcción) en la educación, a medida que busca tener en cuenta las especificidades de los estudiantes del campo.

Palabra clave: educación del campo, caracterización de los educadores, percepción de los educadores, infraestructura de la escuela.

\section{Introdução}

A situação político-econômica do campo foi dominada pela herança coronelista do nosso passado, que relegava a este espaço uma condição marginal no processo de desenvolvimento do país e justificava a carência de qualquer política de bem-estar social (Moreira, 2009).

Alguns pesquisadores detectaram problemas relacionados à educação na área rural, envolvendo diversos aspectos, desde a infraestrutura até a qualidade do ensino ministrado. De modo geral, a manutenção das estradas é precária e não há conservação das escolas que ficam esquecidas pelas políticas públicas da maioria dos municípios. Este descaso se reflete também na baixa qualidade do ensino oferecido, com professores mal remunerados e que não se sentem motivados para exercer um bom trabalho. Sobre isso, Hage (2006) afirma:

No meio rural, os sujeitos se ressentem do apoio que as Secretarias Estaduais e Municipais de Educação deveriam dispensar às escolas, sentindo-se discriminados em relação às escolas da cidade, que assumem prioridade em relação ao acompanhamento pedagógico e formação dos docentes. Os gestores públicos justificam a ausência do acompanhamento pela falta de estrutura e pessoal suficien- 
te para realizar a ação. Essas situações no conjunto associam a multissérie aos prejuízos na aprendizagem, motivando os sujeitos do campo, a considerá-la "um mal necessário" e perseguirem sua transformação em turmas seriadas, como alternativa para que o sucesso na aprendizagem ocorra. (p. 4)

Alencar (1993), citado por Beltrame (2010), também afirma que o professor do meio rural enfrenta uma série de dificuldades causadas tanto pela infraestrutura deficiente dos prédios escolares, quanto pela precariedade salarial e falta de oportunidades para a formação adequada ao desempenho da profissão. Esse professor, na maioria das vezes, com formação incompleta, aceita sem questionar as condições que lhe são propostas ou impostas, com salário que, em certas regióes do país, mal paga o custo de deslocamento até o trabalho. Nesse sentido, vale destacar que a história desses professores sempre esteve ligada a um contexto que aproxima a escola rural da pobreza, das classes multisseriadas, da criança sem lápis e sem caderno, sem sapatos e sem alimentação adequada para enfrentar a distância que separa a casa da escola.

Diante do quadro dramático em que se encontrava a educação nos assentamentos, o Movimento dos Trabalhadores Rurais Sem Terra (MST), a Universidade de Brasília (UNB), a Organização das Nações Unidas para a Educação, Ciência e a Cultura (UNESCO), o Fundo das Nações Unidas para a Infância e Adolescência (UNICEF), a Conferência Nacional dos Bispos do Brasil (CNBB) e a Comissão Pastoral da Terra (CPT) promoveram, juntos, o I Encontro Nacional de Educadoras e Educadores da Reforma Agrária (ENERA), em Brasília, no ano de 1997, que deu origem ao Programa Nacional de Educação na Reforma Agrária (Pronera) (Silva, 2010).

O Pronera surgiu oficialmente, por meio da Portaria 10/1998, para combater parte deste problema, pois seu objetivo principal é fornecer educação de qualidade para jovens e adultos (acampados e assentados) da reforma agrária.

Segundo o autor, ainda em 1998, o MST e seus parceiros realizaram, em Luziânia (GO), a I Conferência Nacional por uma Educação Básica do Campo, que se tornou um marco para a política pública de alfabetização, escolarização e profissionalização na modalidade Educação de Jovens e Adultos em áreas de acampamentos e assentamentos da reforma agrária.

O compromisso dessas instituições, de acordo com Bello (2001), foi o de sensibilizar e mobilizar a sociedade e os órgãos governamentais para os dilemas do campo brasileiro, especialmente o direito à educação para 
os povos do campo que formam a população rural brasileira, como os camponeses, indígenas, pescadores, ribeirinhos, entre outros.

Pereira (2008) afirma que o Pronera visa a contribuir para

a permanência do homem no campo e à conquista de sua autonomia enquanto cidadão consciente de seu papel social. O Projeto, sendo fruto da incansável luta dos movimentos sociais do campo, desponta no país com a missão de ampliar os níveis de escolarização formal dos trabalhadores rurais assentados, fortalecer o mundo rural como território de vida em todas as dimensões da vida humana econômica, social, ambiental, política, cultural e ética - e executar políticas de educação em todos os níveis de ensino. (p. 29)

Para Molina (2010), desde o seu início, o Pronera já beneficiou mais de 400 mil trabalhadores rurais, com escolarização que envolveu desde cursos de alfabetização até cursos superiores.

A Educação do campo surgiu, portanto, da rejeição dos conteúdos e métodos da "educação rural" por parte dos movimentos sociais do campo e de instituições (igreja católica, universidades, ONGs, etc.) que os apoiavam. Essas entidades se organizaram e começaram a reivindicar alguns direitos, por meio dos quais pudessem contribuir para a adaptação da educação às características desta população, propondo moldar a educação ao mundo do trabalho do campo e ao modo de vida das famílias.

Naquela época, já havia respaldo legal para a implantação da Educação do Campo, pois a Lei 9.394/96, em seu artigo $\mathrm{n}^{\circ} 28$, determinava que, na oferta da Educação Básica para a população rural, os sistemas de ensino deveriam promover as adaptações necessárias quanto às peculiaridades da vida rural e de cada região, especialmente:

I- conteúdos curriculares e metodologias apropriadas às reais necessidades e interesses dos alunos na zona rural;

II- organização escolar própria, incluindo adequação do calendário escolar às fases do ciclo agrícola e às condições climáticas;

III- adequação à natureza do trabalho na zona rural. (Saviani, 1997, p. 172)

Fernandes e Molina (2004) afirmam que as adaptações são necessárias:

Os povos do campo e da floresta têm como base de sua existência o território, onde reproduzem as relações sociais que caracterizam suas identidades e que possibilitam a permanência na terra. E nesses grupos há forte centralidade da família na organização não só 
das relações produtivas, mas da cultura, do modo de vida. Esses grupos sociais, para se fortalecerem, necessitam de projetos políticos próprios de desenvolvimento socioeconômico, cultural e ambiental. E a educação é parte essencial desse processo. (p. 61)

O Conselho Nacional de Educação já havia definido a Educação do Campo como "toda ação educativa desenvolvida junto às populações do campo", fundamentada "nas práticas sociais constitutivas dessas populações: os seus conhecimentos, habilidades, sentimentos, valores, modo de ser, de ver, de viver e de produzir e formas de compartilhar a vida" (Art. $2^{\circ}$ da Resolução 01 - CNE 03/04/2002 - Diretrizes Operacionais para Educação do Campo).

Segundo Kolling et al. (1999), citado por Reis (2004), a Educação do campo deve atender aos interesses e ao desenvolvimento sociocultural e econômico dos povos que habitam e trabalham no campo, contemplando as suas diferenças históricas e culturais, para que vivam com dignidade e para que, organizados, resistam contra a expulsão e a expropriação. Cabe construir escolas do campo, e não apenas no campo, ou seja, as escolas precisam ter um projeto político pedagógico vinculado às causas, aos desafios, aos sonhos, à história e à cultura do povo trabalhador do campo. Dessa forma, a Educação do Campo estará contribuindo de forma estratégica para a defesa do desenvolvimento socioeconômico, de forma justa, e ecologicamente sustentável.

Nessa perspectiva, é importante investigar como está ocorrendo o processo educativo em cada local ou região. Assim, o presente artigo parte de uma pesquisa realizada na Escola Municipal Rural São Joaquim Pólo (EMRSJP), ${ }^{1}$ em Selvíria (MS), situada a cerca de $60 \mathrm{~km}$ do núcleo urbano - busca contribuir com esse conhecimento; com o objetivo de verificar se, nessa escola, estão sendo utilizados os princípios pedagógicos e a abordagem metodológica preconizada pela Educação do Campo, de modo a atingir uma aprendizagem verdadeiramente universal e que, portanto, inclua as particularidades, a valorização da vida cotidiana e da cultura dos educandos, como preconiza Caldart (2004). Também analisa como os educadores compreendem a educação do campo, a profissão que exercem e como percebem o público ao qual estão vinculados. 


\section{A pesquisa na Escola Municipal Rural São Joaquim Pólo em Selvíria (MS)}

Inicialmente, foi realizada uma revisão bibliográfica sobre o tema da educação do campo e algumas pesquisas em fontes secundárias (Semac-MS, Prefeitura de Selvíria e IBGE), além de terem sido feitos contatos com a Secretária Municipal de Educação de Selvíria.

A pesquisa de campo foi realizada em dois períodos: no início do mês de junho e no mês de agosto de 2011, na Escola Municipal Rural São Joaquim Pólo, em Selvíria (MS). As visitas à escola ocorreram no período de aulas, para a aplicação dos instrumentos formais de coleta de dados e o acompanhamento do cotidiano da instituição. Foram pesquisados 10 professores (de um total de 18) que se prontificaram a responder um questionário, no qual foram levantados os seus dados pessoais, se já haviam exercido outra profissão, o tempo de trabalho na instituição, se participaram do curso Programa Escola Ativa do Ministério da Educação e se estavam conseguindo pôr em prática as propostas pedagógicas preconizadas pela Educação do Campo. Com todos os professores, foi verificada qual a metodologia de ensino utilizada em sala de aula e a sua percepção a respeito dos alunos da Escola São Joaquim.

Aplicou-se ainda um questionário com algumas questões específicas à diretora e, posteriormente, foi gravada uma entrevista com ela e com a coordenadora pedagógica, visando a esclarecer os aspectos que não ficaram claros nas respostas dos questionários e aprofundar outras questões relativas à infraestrutura e ao funcionamento da escola, bem como à educação do campo. Vale destacar, nesse caso, a importância da observação direta realizada durante todo o período de aplicação dos instrumentos formais da pesquisa.

\section{Características gerais da Escola Municipal Rural São Joaquim Pólo}

A Escola Municipal Rural São Joaquim Pólo está localizada a cerca de 60 km do município de Selvíria (MS). O prédio foi doado pela Associação dos Produtores do Assentamento São Joaquim, mas ainda dependia de regularização no Incra. A construção é muito bonita, tem varandas em "L" e foi adaptada para tentar oferecer um ambiente adequado para os alunos. Em 2011, contava com classes da Educação Infantil até o $2^{\circ}$ ano do Ensino Médio, porém com apenas nove salas para atender 240 alunos (um total 
de 20 turmas, sendo 11 no período matutino e 9 no período vespertino). Nas salas de aula, havia carteiras, mesa para o professor, lousa branca e ventilador. No prédio principal da escola, também havia uma sala de informática; quatro banheiros (um para os alunos do ensino infantil, dois para as demais séries, divididos por sexo, e um para todos os professores); estantes e livros em uma biblioteca instalada provisoriamente no corredor da escola. Com entrada pela lateral do prédio, havia uma cozinha e um refeitório; no lado externo, um espaço de terra batida com uma rede para a prática do voleibol.

A falta de espaço para o atendimento de todas as séries fez com que a direção da escola deslocasse o Ensino Médio ( $1^{\circ}$ e $2^{\circ}$ anos) para uma dependência (casa antiga) fora do corpo da escola, situada a poucos metros dela, mas em situação muito precária (paredes com rachaduras, sem pintura, banheiro precário e mal conservado, teto sem forro e com goteiras).

Com o objetivo de tentar se enquadrar ao propósito da Educação do Campo, a Secretaria da Educação do município ofereceu, de junho a dezembro de 2010, com duração de 200 horas, um curso de formação continuada aos educadores do $1^{\circ}$ ao $5^{\circ}$ ano da escola, ligado ao Programa Escola Ativa do Ministério da Educação, que foi ministrado pela diretora da EMRSJP e pela coordenadora municipal do Programa Escola Ativa em Selvíria, lotada na Secretária Municipal de Educação, após passarem por um processo de capacitação em Campo Grande (MS).

\section{A visão da diretora sobre a escola e sobre o trabalho que realiza}

A diretora da Escola Municipal Rural São Joaquim Pólo é uma moradora do campo e, quando criança, estudou em uma escola na área rural, em sala multisseriada. Como lecionou durante muitos anos nesse tipo de escola, conhece a trajetória da educação no meio rural da região. É uma pessoa com facilidade de comunicação e mostrou-se bastante comprometida com os vários segmentos que compõem a escola (alunos, professores, demais funcionários e comunidade). Parece lidar com a responsabilidade hierárquica com tranquilidade, exercendo sua função sem colocar-se como superior (em seu uniforme, por exemplo, preferiu que constasse o nome "professora" em vez de "diretora" e, quando questionada sobre isso, afirmou: "estou diretora, mas sou professora"). A afinidade com a coorde- 
nadora pedagógica (ex-colega de graduação) também contribui para que a gestão da escola seja equilibrada e eficiente.

Em relação ao público atendido pela escola, a diretora afirmou estar muito satisfeita e que os alunos, em sua grande maioria, são educados e tranquilos. Também considera que os estudantes jovens da escola têm consciência dos seus deveres e as crianças são responsáveis com os afazeres escolares. Sobre a aprendizagem dos alunos, ela avaliou que todos têm capacidade e competências individuais para aprender, pois cada indivíduo é um ser único, passível a ter uma formação satisfatória mesmo com diferenças específicas.

Nesse sentido, Dias (1999) afirma:

Para que elas [as crianças] se percebam cada qual como única, com suas maneiras de pensar, seus gostos, suas preferências, sua forma de agir e reagir diante das situações diversas é fundamental que sejam respeitadas pelo que são e que exista espaço para diferentes comportamentos, não padronizados, que realmente sejam capazes de distinguir um determinado sujeito, diferenciando-o dos demais. A escola cabe contribuir para que esse processo se desenvolva, respeitando as diferenças e não buscando homogeneizá-las. O convívio com o outro, com o diferente, enriquece e aumenta as possibilidades de interlocução. (p. 192)

A diretora demonstrou estar sempre atenta a tudo o que acontece na escola e ser bastante atenciosa e educada. Fazia pausas na entrevista para atender aos alunos, além de ter paciência para ouvir as suas solicitações; ao sairmos, na porta, esperou que um grupo de alunos passasse, dando-lhes preferência.

Em relação ao Projeto Político Pedagógico adotado pela Escola M. R. São Joaquim Pólo, afirmou que se trata da proposta pedagógica da educação do campo, que respeita as diferenças, contempla a diversidade do campo e todos os aspectos sociais e econômicos. Parte dos professores fez o curso do Programa Escola Ativa destinado aos professores do $1^{\circ}$ ao $5^{\circ}$ ano. Ela também contou que esses docentes já estão colocando em prática o que aprenderam e utilizam a referida metodologia desde junho de 2010. Estes aspectos são importantes, pois como afirma Caldart (2008):

A educação do Campo nasceu também como crítica a uma educação pensada em si mesma ou em abstrato; seus sujeitos lutaram desde o começo para que o debate pedagógico se colasse a sua realidade, de 
relações sociais concretas, de vida acontecendo em sua necessária complexidade. (p.72)

A diretora considera que a escola tem conseguido o apoio dos pais, visto que eles sempre estão presentes nas reuniões e mostram-se participativos, colaborando com a formação dos filhos, especialmente para que cumpram o Tempo-Comunidade, isto é, as atividades que os alunos devem resolver quando estão com a família nas propriedades/lotes, entre sexta-feira e domingo de cada semana.

A grande dificuldade, segundo a diretora, refere-se à distância de um centro urbano combinada com a falta de meios de comunicação, inclusive para os casos de emergência. O local onde a escola está situada não possui sinal para ligações com telefones celulares, não há telefone fixo nem acesso à internet. A diretora apontou a dificuldade de interação com os órgãos públicos da cidade, as instalações físicas insuficientes (como a falta de salas de aula para todas as turmas, de salas para os professores, para a direção e para a coordenação, a falta de dormitórios para os professores que passam a semana na escola) e também a falta de alguns equipamentos adequados para a realização do trabalho.

Quanto aos aspectos positivos do trabalho feito na escola, a entrevistada ressaltou a boa interação entre a escola e a comunidade e elogiou os professores, destacando o comprometimento de cada um deles com o desenvolvimento da escola, o que permite dividir os encargos e descentralizar o trabalho de gestão.

\section{Características e visão dos professores da Escola M. R. São Joaquim Pólo}

A pesquisa feita com os professores buscou verificar como eles organizam suas atividades de ensino, como é a sua percepção sobre os alunos e a visão que possuem da Educação do Campo e de sua profissão.

Dos 10 professores pesquisados que ministram aulas para os três níveis de ensino - Educação Infantil, Ensino Fundamental e Ensino Médio -, oito são de procedência da área urbana e apenas dois são moradores da área rural (assentamento).

O perfil do corpo docente é relativamente heterogêneo. Quanto ao sexo, são sete mulheres e três homens; e em relação ao estado civil, cinco professores são casados, três são solteiros e dois divorciados. Quanto à 
faixa etária, a maioria é relativamente jovem, sendo que quatro professores têm de 23 a 30 anos, três de 31 a 37 anos e os outros três têm entre 43 e 49 anos.

Esse grupo pesquisado mescla maior e menor experiência de ensino: quatro têm de 1 a 5 anos de atuação como professor; três têm de 6 a 9 anos; um professor apresenta 15 anos; outro 16 anos de experiência de docência e um deles não informou o tempo que trabalha como educador.

Quanto ao tempo em que exercem a profissão na Escola Municipal Rural São Joaquim Pólo, dos 10 professores pesquisados, três trabalham lá há menos de um ano, dois há um ano, três há um ano e meio, um professor trabalha há dois anos e um deles não respondeu à pergunta. Portanto, entre aqueles que responderam a esta questão, apenas um professor está lá desde o início da ampliação desse tipo de atendimento e da criação da escola como unidade autônoma, em 2010.

Sobre o exercício de outra profissão além de professor, houve certo equilíbrio, pois seis professores responderam que somente trabalharam na atividade de docência, quatro entrevistados disseram que exerceram outras profissões: doméstica (dois), balconista (um) e vigilante sanitário (um). Observa-se, nesses casos, que o trabalho como educador significou um avanço para a qualificação profissional e, provavelmente, uma melhoria na remuneração do trabalho.

Em relação à formação dos professores pesquisados, observou-se que apenas dois deles não possuem curso superior: um está cursando Pedagogia e o outro apenas concluiu o curso de magistério (Ensino Médio). Os professores possuem formação em várias áreas; três são graduados em Pedagogia, três concluíram o curso de Matemática, dois de Letras, um de Geografia (licenciatura e bacharelado) e um de História (licenciatura e bacharelado). Dois professores, além da graduação, possuem pós-graduação, um em Linguística e o outro em Psicopedagogia.

Também se verificou que quatro professores ministram aulas somente na disciplina específica em que possuem formação (inglês, história, geografia e matemática). Um professor leciona para o $1^{\circ}$ e $2^{\circ}$ ano do Ensino Fundamental, mesmo tendo formação em Pedagogia e pós-graduação em Linguística. Cinco professores lecionam apenas do $1^{\circ}$ ao $5^{\circ}$ ano do Ensino Fundamental, são pedagogos. Trata-se, portanto, de um corpo docente com qualificação formal adequada. 
Além disso, 70\% dos professores pesquisados que ministram aulas na Escola São Joaquim foram contratados pela secretária municipal da educação; $20 \%$ dos professores foram selecionados em conjunto com a secretária da educação e a diretora, e apenas 10\% dos professores foram contratados por indicação de um colega, com posterior avaliação da direção. Em alguns casos, foram feitos convites (em virtude do conhecimento que a secretária ou diretora possuía em relação ao docente) e, em outros, os profissionais foram selecionados a partir de currículos entregues na Secretaria Municipal de Educação de Selvíria. É válido ressaltar que os professores não foram designados contra a vontade, mas selecionados e convidados para assumir as aulas na Escola M. R. São Joaquim Pólo. Beltrame (2010) afirma que pesquisas sobre o ensino no campo mostram que é frequente a presença de professores com baixa qualificação e que aceitam trabalhar e receber salários aviltantes nas escolas rurais por não terem outra opção, o que reflete negativamente na qualidade do ensino ministrado.

É uma constante nesses estudos a afirmação de que o professor do meio rural enfrenta uma série de dificuldades, causadas tanto pela infraestrutura deficiente dos prédios escolares, quanto pela precariedade salarial e falta de oportunidades para a formação adequada ao desempenho da profissão. Esse professor, na maioria das vezes sem formação formal oferecida pelo sistema de ensino, aceita passivamente as condições que lhe são propostas ou impostas, com salário que, em certas regiões do país, mal paga o custo do transporte para recebê-lo. (Alencar, 1993, citado por Beltrame, 2010, p. 2)

Entre os professores pesquisados, cinco responderam que não fizeram o curso do Programa Escola Ativa oferecido pela Secretaria Municipal da Educação, em convênio com o Ministério da Educação, pois ministram aulas somente para o segundo ciclo do Ensino Fundamental (do $6^{\circ}$ ao $9^{\circ}$ ano) e para o Ensino Médio. O curso foi destinado apenas aos professores que lecionam do $1^{\circ}$ ao $5^{\circ}$ ano do Ensino Fundamental, sendo que três deles já fizeram o curso e os outros dois professores estavam realizando (em agosto de 2011).

A opinião dos professores sobre o curso ministrado pela Secretaria da Educação é muito positiva. Dois dos professores enfatizaram os novos conhecimentos proporcionados: "deu nova visão sobre o processo ensino e aprendizagem" e trouxe "um novo aprendizado"; outros dois professores destacaram a adequação do curso à realidade do campo, considerando- 
-o muito pertinente "por estar totalmente relacionado com a escola do campo" ou porque "se encaixou na Escola São Joaquim e deu certo"; um dos professores disse que acredita que o curso proporciona melhoria na qualidade do ensino e ajuda a desenvolver valores éticos, cívicos e democráticos; outro professor afirmou que o curso oferece material pedagógico que lhes proporciona maior flexibilidade de ensino das disciplinas.

Todos os professores que participaram do curso afirmaram que colocaram em prática a proposta pedagógica da Escola Ativa e citaram alguns exemplos da metodologia que estão utilizando. Um professor disse que utiliza o caderno de ensino e aprendizagem, o alfabeto móvel, os jogos das sílabas e o material dourado. Outro professor mencionou que lança mão da caixa de sugestões, caixa de compromisso e do cartaz dos combinados (uma espécie de acordo entre o professor e os alunos sobre alguma meta pedagógica ou comportamental que se pretende alcançar). $\mathrm{O}$ ambiente alfabetizador e os kits pedagógicos oferecidos pelo curso foram mencionados por um dos professores; outro afirmou que coloca em prática as propostas por meio da arte e da música, explorando o contexto regional. Há ainda um professor que utiliza também o caderno de ensino e aprendizagem, o material dourado, o diário de leitura e o comitê de leitura, entre outros materiais. Os professores que lecionam no $2^{\circ}$ ciclo $\left(6^{\circ}\right.$ e $9^{\circ}$ anos) do Ensino Fundamental e no Ensino Médio não relataram que utilizam algum material ou seguem um processo especificamente dirigido aos alunos do campo. ${ }^{2}$

Quanto às metodologias em geral utilizadas em sala de aula, cinco professores mencionaram que empregam recursos propostos pela Escola Ativa; um professor relatou que dá aula expositiva com a utilização da lousa, de livros didáticos e equipamentos multimídias; um professor mencionou que usa livros didáticos, globo terrestre, mapas e vídeos para o estudo dos conteúdos, outro citou a utilização de material concreto, quando possível, sempre voltado para o cotidiano dos alunos e dois professores não responderam a esta questão.

Também foi solicitada aos professores uma avaliação sobre os alunos da escola e, caso tivessem uma experiência anterior, que fizessem a comparação com alunos de outras escolas. Não houve consenso: quatro professores destacaram aspectos diferenciais e três acharam que os estudantes são iguais aos da cidade. Entre os que mencionaram diferenças em relação aos alunos da cidade, um professor considerou que os alunos da 
Escola Municipal Rural São Joaquim Pólo têm mais compromisso e boa receptividade com as atividades propostas a eles, além de serem humildes; os outros três professores avaliaram que são disciplinados, mais participativos e têm interesse em aprender o conteúdo estudado, ao passo que os alunos das escolas urbanas em que lecionaram eram indisciplinados e o interesse deles em aprender era menor do que na zona rural. Já os professores que não identificaram diferenças entre os alunos destacaram que a Escola Municipal Rural São Joaquim Pólo diferencia-se de outras escolas pela metodologia empregada, uma vez que busca trabalhar a partir da realidade dos educandos. Outros dois professores não fizeram comparações, sendo que destes um mencionou aspectos positivos dos alunos ("são meigos e esforçados") e um professor considerou que a maioria é irresponsável e não estuda o suficiente para ter um melhor desempenho escolar.

A Escola Municipal Rural São Joaquim Pólo fica a $60 \mathrm{~km}$ da cidade de Selvíria (MS) e a $70 \mathrm{~km}$ da cidade de Ilha Solteira (SP), cidades em que reside a maioria dos professores que lecionam nesta escola. Além da distância, a estrada é de terra e quase todo o ano permanece em estado de conservação ruim (quando chove, fica intransitável para alguns tipos de veículos). Para conseguir exercer a profissão, $80 \%$ dos professores permanecem na escola durante a semana; eles chegam segunda-feira de manhã e só retornam para os seus lares na quinta-feira, após o expediente de trabalho. Nesse período de tempo, improvisam os dormitórios nas salas de aula, colocando os colchões sobre as carteiras escolares, como forma de diminuir o risco de picadas de animais peçonhentos, como cobra, aranha e escorpião, presentes nas imediações da escola.

Foi perguntado aos professores como se sentiam em relação ao desafio de ficar longe de casa e da família durante a semana. As experiências relatadas demonstraram a seriedade destes educadores. Os professores, de modo geral, consideram que foi um grande desafio, visto que há sacrifícios como, por exemplo, a distância da família, a adaptação à experiência e à vivência no meio rural, a falta de comunicação (telefone e internet), a insuficiência de recursos pedagógicos; entretanto, isso tudo tem proporcionado um crescimento pessoal e profissional, pelo convívio diário mais estreito com o grupo. Os dois professores que não permanecem na escola, moram em assentamentos rurais próximos e usam o transporte escolar dos alunos. Os professores que moram na cidade vêm de ônibus escolar específico da Prefeitura Municipal de Selvíria. 
Em relação aos conhecimentos que possuem a respeito das propostas da Educação do Campo, sete professores afirmaram que as conheciam, ao passo que três responderam que não. Cabe destacar que, entre os cinco professores envolvidos no curso do Programa Escola Ativa, dois afirmaram não saber o que é Educação do Campo, pois ainda estão fazendo o curso; já entre os cinco professores que não fizeram o curso, apenas um não sabia o que é isso. Provavelmente, os professores que estão fazendo o curso do Programa Escola Ativa não associaram o termo "educação do campo" com o conteúdo do curso, embora a proposta metodológica seja semelhante. Deve-se destacar também que o conceito de educação do campo está em construção:

O conceito de Educação do Campo é novo, mas já está em disputa, exatamente porque o movimento da realidade que ele busca expressar é marcado por contradições sociais muito fortes. Para nós, o debate conceitual é importante à medida que nos ajuda a ter mais claro quais são os embates e quais os desafios práticos que temos pela frente. No debate teórico o momento atual não nos parece ser o de buscar "fixar" um conceito, fechá-lo em um conjunto de palavras: porque isso poderia matar a ideia de movimento da realidade que ele quer apreender, abstrair, e que nós precisamos compreender com mais rigor justamente para poder influir ou intervir no seu curso. (Caldart, 2007, p. 2)

Ao opinar sobre o que pensam sobre a Educação do Campo, a maioria dos professores que conhecia a proposta a considerou importante e mencionou o fato de que a ênfase dessa abordagem político-metodológica é trabalhar a realidade e o cotidiano do aluno, sendo adequada para a Escola M. R. São Joaquim Pólo. Um professor associou a pergunta ao processo de flexibilidade da grade curricular do Ensino Médio, dizendo que concorda com o processo, desde que o aluno também tenha as disciplinas e os conteúdos exigidos no vestibular.

Quanto à maior dificuldade de trabalho na escola, cinco professores identificaram a falta de comunicação (telefone, internet) e dois indicaram a falta de material didático e paradidático. $\mathrm{O}$ transporte escolar e a distância da cidade também foram mencionados, cada um, por dois professores. Dois deles afirmaram não ter dificuldades, porque a "escola é um sonho de muitos anos que se tornou realidade" e porque tem a colaboração da coordenadora pedagógica, além de muita pesquisa. 
Em relação aos aspectos positivos em trabalhar na Escola São Joaquim, quatro professores mencionaram o crescimento pessoal e as boas relações pessoais estabelecidas no âmbito da escola ("Gosto muito, me sinto em casa, aqui somos uma família, sempre contando com o apoio de todos"); a ampliação dos conhecimentos, a aprendizagem e a boa relação entre professores e alunos foram citadas, cada afirmação, por três professores. Outros fatores como reconhecimento pessoal do trabalho, proximidade com a realidade dos alunos, gosto pela profissão e até a economia das despesas de casa e o fato de não ter progressão continuada foram citados (uma menção para cada uma dessas respostas).

A questão sobre remuneração foi feita de forma geral, isto é, sobre o salário do professor e não diretamente sobre o salário que recebiam. A maioria dos professores pesquisados avaliou que faltam respeito e valorização pelos educadores, que o salário é vergonhoso, mas cabe à categoria refletir, unir-se e reivindicar um salário justo, pois é a educação que poderá garantir um futuro melhor para todos. Um professor mencionou que o incentivo da Educação no Campo deveria ser maior para atrair mais profissionais de qualidade. Dois professores, no entanto, afirmaram que o profissional deve "trabalhar sem pensar no salário, pensar que você está ali para ensinar, e as crianças querem aprender, se durante o ano houver uma aprendizagem satisfatória, isso já basta" e que "se todos desempenhassem mais e reclamassem menos, talvez as coisas melhorassem ao invés de se preocupar somente com o salário”. Dois professores não emitiram opinião sobre o tema.

De modo geral, observa-se que o corpo docente tem formação condizente para o exercício da profissão e uma parte dos professores busca adequar o ensino à realidade dos alunos do campo, especialmente aqueles que frequentaram o curso do Programa Escola Ativa e ministram aulas no primeiro ciclo do Ensino Fundamental (até o $5^{\circ}$ ano). A maioria se mostrou satisfeita com o tipo de público com o qual trabalha e considera que está vivendo uma experiência importante como professor, que convive de uma forma diferenciada com os colegas, os demais funcionários e os alunos.

\section{Considerações finais}

A análise dos dados da pesquisa mostra que a Escola Municipal Rural São Joaquim Pólo, embora implantada recentemente e com vários 
problemas de infraestrutura física (insuficiência de salas de aulas, falta de alojamento para os professores, dificuldades do transporte escolar, de comunicação e de manutenção das estradas), está se constituindo em uma experiência importante de educação no meio rural do município de Selvíria (MS), na medida em que busca considerar as especificidades do campo.

A maneira de compor o quadro docente (após a avaliação do currículo, o professor é convidado e não designado para trabalhar na referida escola); o ótimo envolvimento, tanto da direção quanto do corpo docente e administrativo na organização da escola, para que o processo de ensino-aprendizagem aconteça de forma adequada; a atenção que é possível dispensar aos alunos, já que as turmas são compostas por no máximo 15 alunos; a metodologia e os conteúdos propostos de modo mais próximo à realidade dos estudantes, conforme preconiza a proposta da educação do campo, são fatores diferenciais e relevantes da escola.

A pesquisa constatou também que a maioria dos professores gosta de trabalhar no campo, e especificamente naquela escola, sente-se satisfeita com as características e com o interesse dos discentes.

Por fim, avaliamos que, para a continuidade dessa experiência, é necessário melhorar a infraestrutura da Escola Municipal Rural São Joaquim Pólo e criar alojamentos adequados aos professores, de modo que eles se sintam ainda mais incentivados a continuar lecionando naquela escola. Além disso, também é importante proporcionar a todos os professores a capacitação adequada à educação do campo e não apenas àqueles que ministram aulas nas séries iniciais.

\section{Notas}

1. A referida pesquisa constituiu-se na monografia de conclusão do curso de especialização em Educação do Campo, realizado na Universidade Federal do Mato Grosso do Sul (Campo Grande), em 2011, pela primeira autora deste artigo.

2. Em conversas informais, no entanto, pode-se notar a utilização de práticas ligadas ao campo, como o professor de matemática que ensina medidas de áreas típicas do espaço rural e cálculo de altura de árvores. 


\section{Referências}

ALENCAR, J. F. A professora "leiga": um rosto de várias faces. In: THERRIEN, J.; DAMASCENO, M. N. (Orgs.). Educação e escola no campo. São Paulo: Papirus, 1993.

BELLO, J. L. de P. Educação no Brasil: a história das rupturas. Pedagogia em Foco, Rio de Janeiro, 2001. Disponível em: http://www.pedagogiaemfoco.pro.br/heb14. htm. Acesso em: 10 jan. 2011.

BELtrame, S. A. B. Cenário da escola do campo. Curso de Especialização em Educação do Campo, Eixo Temático II, 2010.

CALDART, R. S. Por uma educação do campo. In: MOLINA, M. C.; JESUS, S. M. S. A. (Orgs.). Contribuições para a construção de um projeto de educação do campo. Brasília (DF): MST, 2004. p. 13-52.

CALDART, R. S. Sobre educação do campo. SEMINÁRIO DO PROGRAMA NACIONAL DE EDUCAÇÃO NA REFORMA AGRÁRIA (PRONERA), 3, Luziânia (GO), 2007.

CALDART, R. S. Por uma educação do campo. In: SANTOS, C. (Org.). Educação do campo: campo - políticas públicas - educação. Brasília (DF): INCRA; MDA, 2008.

DIAS, K. S. Formação estética: em busca do olhar sensível. In: KRAMER, S. et al. (Orgs). Infância e educação infantil. Campinas, SP. Papirus, 1999. p.175-201.

FERNANDES, B. M.; MOLINA, M. C. O campo da educação do campo. In: MOLINA, M. C.; JESUS, S. M. S. A. (Orgs.). Contribuições para a construção de um projeto de educação do campo. Brasília (DF): MST, 2004. p. 53-89.

HAGE, S. M. A realidade das escolas multisseriadas frente às conquistas na legislação educacional. REUNIÃO ANUAL DA ASSOCIAÇÃO NACIONAL DE PÓS-GRADUAÇÃO E PESQUISA EM EDUCAÇÃO (ANPEd), 29, 2006. Disponível em: http://www.anped.org.br/reunioes/29ra/trabalhos/posteres/GT13-2031--Int.pdf Acesso em: 05 fev. 2011.

KOLling, E. J. et al. Por uma educação básica do campo. Brasília (DF): Peres Gráfica e Editora, 1999.

MOLINA, M. C. Educação do campo e desenvolvimento rural sustentável. CONGRESSO LATINO-AMERICANO DE SOCIOLOGIA RURAL, 8, Porto de Galinhas (PE), 2010 (Comunicação Oral).

MOREIRA, F. As imagens sociais produzidas a respeito da "roça". In: SCHÜTZFOERSTE, G. M.; FOERSTE, E.; CALIARI, R. (Orgs.). Introdução à educação do campo: povos, territórios, saberes da terra, movimentos sociais, sustentabilidade. Vitória, ES: UFES, Programa de Pós-Graduação em Educação. 2009. p. 1-3 (Cd-rom).

PEREIRA, F. A. A educação de pessoas jovens e adultas e a cidadania no campo: um olhar sobre o Pronera no norte do Tocantins. João Pessoa (PB), 2008. 134p. Dissertação (Mestrado em Educação) - Universidade Federal da Paraíba (UFPB). Disponível em: http://bdtd.biblioteca.ufpb.br/tde_busca/arquivo.php?codArquivo=662 Acesso em: 20 set. 2011. 
REIS, E. S. Entrelaçando saberes para a construção do desenvolvimento local sustentável. In: SCHÜTZ-FOERSTE, G. M.; FOERSTE, E.; CALIARI, R. (Orgs.). Introdução à educação do campo: povos, territórios, saberes da terra, movimentos sociais, sustentabilidade. Vitória (ES): UFES, Programa de Pós-Graduação em Educação, 2004. p. 1-7 (Cd-rom).

SAVIANI, D. A nova lei da educação: nova LDB, trajetória, limites e perspectivas. São Paulo: Autores Associados, 1997.

SILVA, S. B. Educação do campo para os assentamentos e acampamentos rurais. ENCONTRO DA REDE DE ESTUDOS RURAIS, 4, Curitiba (PR), Anais...Curitiba (PR), 2010 (Cd-rom).

Divanir Zaffani Sant'Ana - Graduado em Letras pela Faculdade Estadual de Filosofia, Ciências e Letras de Cornélio Procópio e em Geografia pelo Centro Universitário Claretiano de Batatais - Especialista em Educação do Campo pela Universidade Federal de Mato Grosso do Sul.

Antonio Lázaro Sant'Ana - Graduado em Engenharia Agronômica pela Universidade de Brasília - Mestre e Doutor em Sociologia pela Universidade Estadual Paulista - Pós-doutor em Sociologia Rural, como bolsista CAPES, no Institut National de la Recherche Agronomique (INRA) e na École des Hautes Études en Sciences Sociales (EHESS), em Paris (França) - Professor adjunto da Universidade Estadual Paulista.

Recebido para publicação em 27 de julho de 2013 Aceito para publicação em 28 de outubro de 2013 